\title{
Correction
}

\section{Correction to: Application of Low-Cost Fixed-Wing UAV for Inland Lakes Shoreline Investigation}

\author{
Tomasz Templin, ${ }^{1}$ Dariusz PopielarczyK, ${ }^{1}$ and Rafaz Kosecki ${ }^{1}$
}

Correction to: Pure Appl. Geophys.

https://doi.org/10.1007/s00024-017-1707-7

Unfortunately the first name of the third author the small letter has been used instead to be capitalized. The name should be read: Rafał Kosecki.

Furthermore the version of 'RAFAt' is incorrect. It should be 'RAFAŁ'.

We apologise this mistakes. The original version has been corrected. 